\title{
TECNOLOGIAS ACESSÍVEIS PARA DEFICIENTES VISUAIS NO AMBIENTE ESCOLAR
}

\author{
English title: ACCESSIBLE TECHNOLOGIES FOR VISUALLY DISABLED PEOPLE \\ IN THE SCHOOL ENVIRONMENT
}

doi>10.33726/akdpapers2447-7656v11a72021p191-207

\author{
PIVETA, Marilisi C. ${ }^{1}$; MENEGUESSO, Nicoli²; TRENTINI, Taís F. ${ }^{3}$ \\ CHAINÇA, Eliane ${ }^{4}$; ALEXANDRE, Kethi C. do R. S. $^{5}$
}

RESUMO: O processo educacional sempre contou com uma lacuna importante com relação ao quesito inclusão. Diversas Leis e políticas públicas têm contribuído para extinguir esse processo, mas nenhuma ferramenta tem sido mais eficaz que a tecnologia, desde que aplicada combinada a métodos específicos ao aprendizado. Justifica a realização deste estudo, a relevância do tema "inclusão" para a sociedade, para o meio acadêmico e para o futuro das novas gerações. O presente trabalho traz como objetivo geral o de compreender a importância das tecnologias acessíveis para deficientes visuais no ambiente escolar. O método utilizado se baseou em pesquisa teórico-bibliográfica, com fundamentação em autores como Carvalho (2008), Sonza (2004) e Oliveira (2015). Como resultados, vê-se que foi possível identificar a real colaboração da tecnologia face aos alunos que têm algum tipo de deficiência, propondo a tecnologia como ferramenta de aproximação do aluno com a sua própria realidade.

PALAVRAS-CHAVE: Inclusão, Tecnologia, Deficiência, Educação

\begin{abstract}
The educational process has always had an important gap in terms of inclusion. Several laws and public policies have contributed to extinguishing this process, but no tool has been more effective than technology, as long as it is applied in combination with specific methods for learning. It justifies the realization of this study, the relevance of the theme "inclusion" for society, for the academic environment and for the future of new generations. The present work has as a general objective to understand the importance of accessible technologies for the visually impaired in the school environment. The method used was based on theoretical-bibliographic research, based on authors such as Carvalho (2008), Sonza (2004) and Oliveira (2015). As a result, it can be seen that it was possible to identify the real collaboration of technology vis-à-vis students who have some type of disability, proposing technology as a tool to bring students closer to their own reality.
\end{abstract}

KEYWORDS: Inclusion, Technology, Disability, Education

\footnotetext{
${ }^{1}$ Graduanda do Curso de Pedagogia da UNIP (Universidade Paulista), São José do Rio Preto - SP. Contato: marilisi piveta@hotmail.com

${ }^{2}$ Graduanda do Curso de Pedagogia da UNIP (Universidade Paulista), São José do Rio Preto - SP. Contato: nicolimeneghesso16@outlook.com

${ }^{3}$ Graduanda do Curso de Pedagogia da UNIP (Universidade Paulista), São José do Rio Preto - SP. Contato: taiszan65@gmail.com

${ }^{4}$ Docente e Orientadora do Curso de Pedagogia da UNIP (Universidade Paulista). Mestra em Educação Escolar - UNESP/FCLAR - Araraquara - SP. Contato: eliane.chainca@gmail.com

${ }^{5}$ Docente e Orientadora do Curso de Pedagogia da UNIP (Universidade Paulista). Doutoranda em Educação - UMESP. Contato: kethicris@hotmail.com
} 


\section{INTRODUÇÃO}

Apesar da pouca visibilidade que se tem dado ao assunto, o desenvolvimento da tecnologia ocorre a todo momento trazendo novas ferramentas e diversas formas de utilizá-las nas relações ensinoaprendizagem. A fim de tratar sobre as tecnologias acessíveis para deficientes visuais no ambiente escolar, a pesquisa apresentará a funcionalidade de softwares, programas e outros aparelhos, com a principal finalidade de compreender a sua importância para a aprendizagem da pessoa com deficiência.

A metodologia adotada foi a pesquisa teórico-bibliográfica, buscando compreender e discutir o tema proposto. Foi efetuado, previamente, um levantamento de livros, artigos e revistas para a coleta das informações necessárias e delimitação do corpus de análise. Em sequência, houve a realização do fichamento do conteúdo que foi fundamentado, principalmente, nos seguintes autores: Rosita Edler Carvalho, Andréa Poletto Sonza e Claudio de Oliveira.

A princípio, o trabalho dissertará sobre as tecnologias inclusivas disponíveis para alunos com deficiência visual, citando quais são elas, para que servem e quais são os indivíduos que prioritariamente se beneficiam delas.

Na segunda parte, acontecerá o desenvolvimento dos assuntos 'inclusão no ambiente escolar' e 'aprendizagem do aluno'. Além disso, ainda nesta parte, serão evidenciadas 'a necessidade do preparo do professor para lidar com as tecnologias' e 'o deficiente visual'.

Por fim, na terceira divisão, será feita a junção dos assuntos anteriores (tecnologias e inclusão do deficiente visual), com destaque ao modo com que ocorre o funcionamento das tecnologias, como são capazes de ajudar e porque são relevantes para o deficiente visual no ambiente escolar. 


\section{AKED霆}

\section{TECNOLOGIAS INCLUSIVAS}

Paraguay (2009), sobre a melhoria na inclusão de pessoas com deficiência no ambiente escolar, complementa a informação, dizendo que, neste cenário, se tem trabalhado de maneira interdisciplinar, e que, desse modo, a participação e a comunicação de indivíduos especiais serão maiores.

Atualmente, ao menos, é assim que o uso da tecnologia é capaz de amparar alunos com deficiência visual na compreensão de novos conhecimentos, na comunicação, no incremento da autonomia e no desenvolvimento cognitivo, promovendo a inclusão escolar e social (FREIRE; VALENTE, 2003). Logo, é importante saber que faz parte do currículo e é dever da instituição escolar, primeiramente, disponibilizá-la e depois utilizá-la com o objetivo de realizar a meta proposta. Entretanto, é válido reforçar que apenas o uso da tecnologia não garante a aprendizagem:

Art. 61. Para os fins deste Decreto, consideram-se ajudas técnicas os produtos, instrumentos, equipamentos ou tecnologia adaptados ou especialmente projetados para melhorar a funcionalidade da pessoa portadora de deficiência ou com mobilidade reduzida, favorecendo a autonomia pessoal, total ou assistida (BRASIL, 2004).

Além da acessibilidade aos recursos tecnológicos, é preciso entender que há pessoas com deficiência visual divididas entre indivíduos com baixa visão e os completamente cegos, podendo ambos serem patologias adquiridas ou congênitas (KASTRUP, 2010). De acordo com essa divisão, a escolha de softwares e as demais ferramentas sofrerá influências.

Entre tantos recursos, Carvalho (1993) distribui as tecnologias para indivíduos deficientes visuais em 03 grupos. São eles: o sistema de leitura ampliada, sistema de saída de voz e o sistema de saída em Braille.

Para pessoas com baixa visão, congênita ou adquirida, há programas como o LentePro e o Magic, que aumentam o tamanho das letras na tela do computador. Muitas escolas também fazem uso do Windows, um sistema operacional capaz de ser ajustado a tais programas (SONZA, 2004).

Os programas leitores de telas são direcionados para indivíduos cegos, com a cegueira congênita ou adquirida. Para Carvalho (1993), há sistemas 


\section{AKEDIA}

como: o Virtual Vision 5.0, Jaw 8.0 e NVDA, aptos a lerem sites educacionais, jornais e outros conteúdos e o programa Virtual Vision que, além de ler, informa quais controles podem ser usados, descreve imagens e verbaliza o que está sendo digitado no teclado. O Braille Falado também pode ser utilizado, na escola, para edição de texto e sintetizador de voz (SONZA, 2004). E há também inovações, como a Impressora 3D, que imprime objetos em alto relevo (TOMAZ, 2019).

Desenvolvimentos tecnológicos que se comunicam com usuário iniciantes, ampliando a tela, podem ter grande eficiência se usados na escola. Um deles é o programa DosVox, que possui vários meios para a aprendizagem, como: o Biblivox, lugar para fazer pesquisa bibliográfica vocal; o Braivox, habilitado a fazer impressão e conversão de textos para o Braille; o Calcuvox, uma calculadora vocal; e o Beaivox, um impressor de Braille. Esse programa também possui jogos, que podem ser trabalhados de forma educativa, como por exemplo, o Forca Vox (jogo da forca), o Memoria Vox (jogo da memória), o Mistura Vox (jogo de mistura de sons) e o Conta Vox (jogo de tabuada) (SONZA; SANTAROSA, 2015).

\section{INCLUSÃO E APRENDIZAGEM DO DEFICIENTE VISUAL NO AMBIENTE ESCOLAR}

Sobre a Educação Especial ou Inclusiva, é possível perceber que recentemente ocorreram muitas mudanças nas políticas públicas e legislações, que indicam um caminho para um atendimento de melhor qualidade aos alunos em situação de desvantagem (CARVALHO, 2008).

Segundo Carvalho (2008), nas últimas décadas, vêm ocorrendo transformações motivadas em prol da inclusão das pessoas com deficiência visual. Nesse contexto, se tem verificado o aumento do ingresso de alunos com deficiências visuais no ensino regular, inclusive no ensino integrado.

Assim, a inclusão dos alunos com deficiência visual desencadeia desafios para a instituição escolar em vários âmbitos, entre eles os que se referem à formação do professor, diante da urgente necessidade de compreender as possibilidades e dificuldades demonstradas pelos docentes na 
atuação com estudantes cegos e com baixa visão matriculados nas escolas regulares e em atendimento nas salas de recursos (CARVALHO, 2008).

Apesar da inserção dos estudantes com deficiência na escola regular já se caracterizar como uma garantia legal e os alunos com comprometimento visual estarem conquistando espaços cada vez maiores no sistema educacional brasileiro, observa-se que sua inclusão ainda ocorre em ritmo de passos lentos (CARVALHO, 2008).

Carvalho (2008) ainda aponta que não é assunto recente a discussão sobre o direito à educação para todos. É um direito garantido em Leis que impulsionam lutas em todos os âmbitos da sociedade por uma educação de qualidade. As legislações dos últimos anos apontam para uma melhora com o intuito de possibilitar a todos os alunos que tenham direito à educação. A referência 'a todos os alunos' significa a inclusão daqueles com síndromes, deficiências, condutas típicas, alunos de classes especiais, ou seja, os que apresentem alguma deficiência ou incapacidade, e por isso necessitam de algum atendimento especial ou complemento.

Apesar da existência de uma série de Leis, ainda se esperam muitas melhorias. Percebe-se, muitas vezes, que pouco tem acontecido e que mudanças simples que permitem, por exemplo, a acessibilidade dos alunos com alguma desvantagem à escola ou aos demais ambientes que possibilitem seu crescimento, não é realizada (CARVALHO, 2008).

De acordo com Magri (2011), a inclusão de alunos com necessidades educacionais especiais nas escolas regulares, vem buscando sua institucionalização e normatização do ensino igualitário, com qualidade, preservando o respeito às diferenças contidas no ambiente escolar.

Como enfatiza Carvalho (2008), a escola como um todo é o lugar da aula. Porém, é necessário mudar essa concepção tradicionalista. Ainda segundo o autor, uma ideia interessante é tornar a escola um laboratório de aprendizagem, um lugar de pesquisa e de conhecimento.

De acordo ainda com Carvalho (2008), os processos de transformações sociais afetam diretamente o sistema educacional e, consequentemente, a aprendizagem do aluno. Para o autor, a escola precisa reciclar-se para assumir 


\section{AKEDIA}

o papel como agente de mudanças, geradora de conhecimento, formadora de sujeitos capacitados a intervir e atuar na sociedade de forma crítica e criativa.

Diante desse contexto, torna-se indispensável a construção de uma escola inclusiva, estando aberta para receber alunos com deficiência e estabelecendo relações significativas para o futuro dos educandos, tornando-os cidadãos capazes de lidar com os desafios e dificuldades impostas pela sociedade (CARVALHO, 2008).

A relação professor-aluno deve ser de respeito e afeto. Porém, para complementar essa boa relação, é necessário que o professor leve para sala de aula práticas pedagógicas que contribuem nesse sentido, promovendo um distanciamento do tradicionalismo e aproximando os educandos do processo de elaboração das aulas, desenvolvendo-as, desde a escolha dos temas a serem abordados até a participação direta nas atividades (RIBEIRO, 2017).

Ribeiro (2017) afirma que a Educação Especial, na perspectiva inclusiva, tem papel imprescindível e não pode ser negada, embora dentro dos limites de suas atribuições, sem extrapolar seus espaços de atuação específica. Com isso, as escolas precisam se adaptar às necessidades específicas de seus alunos, buscando não apenas a aceitação do aluno com deficiências visuais nas classes regulares de ensino, mas, sim, fazer valer de fato a educação inclusiva, enfrentando desafios e buscando melhorias na qualidade do ensino.

A educação hoje, já não pode mais manter-se somente como acadêmica ou profissionalizante, por isso necessitamos de professores que conheçam o sistema produtivo e principalmente as inovações tecnológicas. Portanto, o professor deve sempre procurar a atualização profissional e pessoal (MAGRI, 2011).

Para Magri (2011), o ponto inicial desse processo é o professor, que também é o organizador da atividade escolar. O processo de incorporação desta tecnologia no trabalho do professor deve ser efetivado em fases. A informática aplicada a um processo educacional, consiste no uso da tecnologia da informação, ou seja, de informações armazenadas em meio magnético, para o desenvolvimento de atividades educativas, individuais, ou coletivas, com o objetivo de ampliar as possibilidades de acesso e manipulação das 
informações, como também de desenvolvimento e aprimoramento dos processos cognitivos por intermédio de softwares.

Não se trata do uso do computador exclusivamente, nem mesmo do seu uso em ambiente reservado dentro da escola, mas, sim, da incorporação deste novo paradigma tecnológico perpassando por todos os espaços escolares e sendo incorporado por todos os sujeitos que interagem nesse ambiente (MAGRI, 2011).

Para Magri (2011) o professor primeiro necessita ter contato com essa tecnologia, de uma forma voltada para o seu cotidiano para que ele possa se familiarizar e, só então, depois, utilizar para desenvolver habilidades ou reforçar conteúdos.

\title{
3. TECNOLOGIAS E A INCLUSÃO DO DEFICIENTE VISUAL
}

Segundo Carvalho (2011), o acesso à tecnologia ajuda no processo de comunicação e interação com o auxílio de ferramentas específicas e de softwares, com o objetivo de atender o indivíduo com necessidades especiais.

Rabello (2007, p. 36), enfatiza que o computador é um recurso interessante, que desperta $o$ interesse da criança e que deve ser explorado pelo professor:

\begin{abstract}
É um equipamento versátil, que permite o deslocamento de figuras, símbolos e cenas e favorece a coordenação visomotora. Essa importante função visual, associada às demais funções cerebrais, favorece o aprendizado da leitura e escrita, essenciais para o processo educativo e indispensável veículo de cultura. $O$ excelente padrão de cor e contraste facilita a discriminação das figuras, ajusta as condições de iluminação do ambiente, para torná-lo adequado às necessidades visuais do usuário e faz a adequação da fonte, dos espaços entre os exercícios e dos traçados, de acordo com as condições visuais do indivíduo (CORSI, 2001, p. 36).
\end{abstract}

Carvalho (1993) cita três tipos de tecnologias disponíveis para pessoas com deficiências visuais. A primeira, é o sistema de leitura ampliada, que se divide em duas formas: os ampliadores de telas e os ampliadores de imagens. Ampliadores de telas encaixam-se para quem tem baixa visão. Eles permitem o aumento da letra, zoom, mudança de cor, contraste de letras e figuras. Os ampliadores de imagens, chamados CCTV (closed circuit television) ou circuito 


\section{AKEDIA}

fechado de televisão, permitem ler textos manuscritos ou impressos, podendo ampliar em até 60 vezes o tamanho de um ícone.

A segunda tecnologia, é o sistema de saída de voz, que se fazem representar por meio de leitores de tela como os softwares usados no Brasil (DosVox, Virtual Vision e Jaws).

A terceira interface tecnológica, trata do sistema de saída em Braille que, no caso, se expressa fisicamente por meio da Impressora Braille.

Segundo Sonza (2004), no mercado existem variedades e mudam algumas características de uma para outra, tamanhos, velocidade, tais como o Braille interponto (impressão dos dois lados do papel), e demais congêneres.

Outro equipamento é o Thermoform, que é como uma máquina de Xerox, o material sai em relevo em uma película de PVC. O Terminal Braille é um equipamento que é ligado ao computador através de um cabo, e normalmente esse Terminal é encaixado em um teclado comum, formando uma linha a mais.

O Braille Falado é um sistema de armazenamento de dados, que é feito mediante um teclado Braille de seis pontos, e a saída é efetuada a partir de um sintetizador de voz. E, por fim, existe também o Braille Lite, que funciona como um caderno de notas, calendário e agenda.

Para deficientes que possuem baixa visão, os sistemas mais utilizados no Brasil são os LentePro. Nele, o que aparece na tela é ampliado em uma janela, como se fosse uma lupa e, assim, se permite que o usuário veja todos os detalhes, mesmo com um grau baixo de visão.

O sistema Magic, que também é voltado para deficientes com visão subnormal, é mais completo que o LentePro. Suas ferramentas permitem a alteração de cores e contrastes, e o aplicativo pode fazer leitura da tela utilizando uma voz sintetizada. Os sistemas como DosVox, Virtual Visio, Jawse NVDA são voltados para os sujeitos com perda total de visão (SONZA, 2004).

O DosVox, é um sistema para microcomputadores e se comunica com o usuário via síntese de voz e gera um sistema de "conversa" com o deficiente visual em português. O sistema é pioneiro nessa área, disponibilizando um sistema completo para cegos, que permite editar vídeos e navegar na internet, além do uso de utilitários (SONZA, 2004). 


\section{AKED霆}

Sonza (2004), ressalta também o Virtual Vision, que é um "leitor de telas", capaz de informar quais controles (lista, botão, menu etc.) estão ativos em determinado momento. Atualmente este dispositivo é acessado por 4.500 pessoas e também pode ser utilizado para navegar na internet.

Jaws, outro sistema voltado para deficientes visuais, possibilita uso da grande maioria dos aplicativos existentes como: Office, Internet Explorer, Outlook Express, Chat e outros. Além disso, esse sistema é facilmente instalado com apoio de voz durante o procedimento. O NVDA (Nonvisual Desktop Access) também é um leitor de telas para o sistema operacional Windows.

Sonza (2004) menciona que a impressora 3D tem sido introduzida em algumas escolas do Brasil, podendo reproduzir objetos, pinturas clássicas, mapas em alto relevo e muitos outros objetos, sendo uma boa maneira de gerar um protótipo de um objeto.

Carvalho (2011) cita que o Sistema Braille tem grande importância e ajuda de muitas formas um aluno com deficiência visual e que utilizando esse sistema que um aluno cego pode ser alfabetizado. Além disso, proporciona-se ao aluno maior independência na escrita e leitura e consequentemente maior facilidade de comunicação e socialização.

A Lei de Diretrizes e Bases da Educação Nacional (LDB, Lei 9.394/96) estabelece que o dever do Estado com a educação escolar pública será efetivado mediante diversas garantias, entre elas 0 atendimento educacional especializado gratuito aos alunos com necessidades especiais, preferencialmente na rede regular de ensino. O projeto de Lei 444/11, aprovado na Câmara dos Deputados, obriga as escolas públicas e privadas a alfabetizarem alunos pelo sistema de leitura em Braille.

Segundo Sonza e Santarosa (2015), o DosVox, mais completo e o mais utilizado, possui inúmeros acessos que beneficiam o deficiente visual, com baixo custo. Para usuários iniciantes torna-se ideal, pois é de fácil utilização e tem um processamento rápido, além disso, favorece a interação, como Papovox, Cartavox e Webvox.

O DosVox é um sistema operacional para computadores com o qual o usuário se comunica pela voz, ou seja, pela reprodução de fonemas em 


\section{AKEDIA}

português, que são gerados sem o auxílio da pré-gravação. Sua tecnologia é totalmente nacional, sendo o primeiro sistema comercial a sintetizar vocalmente textos genéricos na língua portuguesa (SONZA; SANTAROSA, 2015).

O Virtual Vision também ajuda os deficientes visuais em muitas coisas, por ter ótima síntese de voz (entonação e pontuação) e de fácil distribuição. $O$ sistema Jaws é bem completo, traduzindo para o português e outros idiomas e possui bastante acessibilidade nas leituras de tela. Tecnologias como LentePro e NVDA auxiliam pessoas com visão subnormal a ter melhor percepção de leitura e, através desses sistemas, é possível ampliar imagens, letras, números e até ter contraste de cores, além de ser simples para utilizar, ocupar pouco espaço e permitir várias configurações (SONZA; SANTAROSA, 2015).

Já, a impressora 3D, estimula sentidos do toque, que substituem a visão do objeto. Os óculos inteligentes são um equipamento completo, com eles o deficiente visual pode andar pelas ruas sozinho, pois os óculos têm a opção de ler tudo ao seu redor (placas, nome de comércios etc.) e é transmitido através do fone de ouvido. O equipamento também grava o rosto das pessoas e relaciona com o nome em que o usuário gravar no sistema. Dessa forma, essa tecnologia cria no indivíduo elevado grau de autonomia, independência e socialização (SONZA, 2004).

É notório que a tecnologia tomou conta de todos os setores da sociedade. Não existe nenhum canto do mundo onde a tecnologia não chegue, mesmo quando restrita a alguns equipamentos. No caso da população brasileira, em sua grande maioria, a tecnologia está presente e acessível à palma da mão, literalmente, em smartphones, tablets e notebooks, o que torna o trabalho com a tecnologia mais amigável no ambiente escolar (NACARATO; MENGALI; PASSOS, 2009).

Quando o aluno já possui uma familiaridade com tecnologias como o uso de softwares, apps e acesso à internet, é natural que busque também no seu aprendizado as formas de utilizar o que conhece. Já, para o professor, a utilização da tecnologia amplia os métodos e a própria didática, trazendo novos conteúdos, mais empolgantes e interessantes aos alunos (OLIVEIRA; MOURA; SOUSA, 2015). 


\section{AKED』A}

No entanto, a chamada alfabetização digital não se restringe somente à posse dos equipamentos. Sua utilização demanda da população em geral conhecimento a respeito das funcionalidades. Já, para o professor em especial, se esses formatos não forem devidamente tratados, podem gerar um processo de segregação para os alunos com algum tipo de necessidade especial, por exemplo (OLIVEIRA; MOURA; SOUSA, 2015):

Ainda existe a possibilidade onde o próprio professor não domina o uso da tecnologia, tornando inviável, e até mesmo impossível, a utilização dessas ferramentas em sua didática. Conforme a afirmação dos autores Nacarato, Mengali e Passos: "é impossível ensinar aquilo sobre o que não se tem um domínio conceitual" (NACARATO; MENGALI; PASSOS, 2009, p. 35).

É fácil concordar que, o que não se aprende, não é possível ensinar. Dessa forma, a intervenção deve começar na formação dos docentes, preparando-os para um ensino adequado com a utilização da tecnologia. No que se refere às tecnologias utilizadas com finalidade pedagógica, as mesmas possuem especificações definidas previstas em aparatos legais como a "Norma Brasileira NBR 15.599”, de 2008, cujo objetivo está descrito em sua redação, como segue:

\footnotetext{
Esta Norma fornece diretrizes gerais a serem observadas para acessibilidade em comunicação na prestação de serviços, consideradas as diversas condições e percepção e cognição, com ou sem a ajuda de tecnologia assistiva ou outra que complemente necessidades individuais (ABNT, 2008, n.p).
}

A normativa considera, portanto, a aprendizagem enquanto processo comunicacional, interativo e permanente. Isso se dá pela necessidade de que essas ferramentas estejam disponíveis em versão sonora, além do visual, de forma a incluir alunos que tenham algum tipo de deficiência visual (ABNT, 2008).

De modo geral, a sonoridade se dá a partir da narração do texto ou dos passos que são executados. Em sentido lato, esse tipo de mídia pode ser reproduzida, de lado a lado, via aparelhos como os CD-players, MP3-players e outros dispositivos informáticos (OLIVEIRA; MOURA; SOUSA, 2015). 


\section{AKED』A}

É possível apontar também o método de impressão tátil, útil aos que têm algum tipo de dificuldade visual. Para esse tipo de impressão, que é realizada com o alfabeto Braille, são utilizadas impressoras Braille e máquinas Perkins, que possuem preços viáveis no mercado. Para facilitar o trabalho do educador com esse tipo de método, o Ministério da Educação disponibiliza manuais de grafia Braille adaptado para a informática (MEC, 2018).

Fica nítido, portanto, que a tecnologia aliada à educação traz consigo diversos formatos de ferramentas, que possibilitam inclusive um processo mais assertivo de inclusão. Se, para o aluno com dificuldades visuais, enxergar a letra no quadro negro torna-se um martírio, conseguir participar de uma aula interativa com projeção torna-se bem mais atraente (OLIVEIRA; MOURA; SOUSA, 2015).

Essa característica da tecnologia, que possibilita sua adaptação às necessidades inclusivas, é chamada de tecnologias assistivas, as quais, dentro do processo educacional, têm um valor inestimável. Elas possibilitam o processo de aprendizagem, otimizam as potencialidades de cada aluno, e se tornam imprescindíveis para o aprendizado dos alunos com deficiência (OLIVEIRA; MOURA; SOUZA, 2015).

No que se refere à literatura no processo educacional, esta sempre teve sua valorização. Os livros didáticos e infantis já são um recurso pedagógico presente em salas de aula há muitas décadas, promovendo a criatividade, a imaginação, a ludicidade, além de transmitir lições do cotidiano e desenvolver na criança o senso de contar histórias. No entanto, sempre que é pensado em um processo inclusivo, é natural que o instinto humano imagine um adulto lendo para uma criança com dificuldade (OLIVEIRA; MOURA; SOUSA, 2015).

Com os livros em áudio ou impressos de forma tátil, no entanto, essa criança ganha autonomia e participação como protagonista de seu próprio desempenho. O audiobook torna-se uma poderosa ferramenta nesse sentido, pois dá à criança a possibilidade de ditar seu ritmo de leitura (aprendizado) (OLIVEIRA; MOURA; SOUSA, 2015).

No caso de pessoas com algum tipo de deficiência, os apps inovam ao pensar 'fora da caixa' trazendo possibilidades infinitas, que utilizam áudio, 


\section{AKED』A}

vídeo, movimento, e outras formas de interagir, como a sintetização da voz, reconhecimento de textos e tradução de outras línguas (TORNIERO, 2019).

Um bom exemplo a se mencionar é o software Jecripe, que funciona como um jogo que estimula o raciocínio para alunos com Síndrome de Down. Este aluno ainda pode construir noções de lógica, o que contribui com o seu processo inclusivo (JECRIPE, s/d). Para os alunos com deficiência ou dificuldade auditiva existe o Dicionário da Língua Brasileira de Sinais, com recursos de vídeo em Libras.

As impressoras 3D também se apresentam como uma solução inovadora, contribuído em diversas áreas da sociedade, facilitando o trabalho na construção civil, na medicina e até mesmo na educação. Esse recurso tecnológico possibilita a impressão de livros com relevo, tornando comum o trabalho em Braille realizado em sala de aula (TOMAZ, 2019). Ainda é possível imprimir mapas para as aulas de geografia, objetos tridimensionais como células e outros, possibilitando uma melhor assimilação em ciências, e tantas outras infinitas possibilidades.

No que se refere aos recursos de locomoção, a gestão escolar ainda precisa considerar, além dos equipamentos e recursos tecnológicos, o entorno de sua atuação, já que a inclusão começa pelo propósito da acessibilidade. Os alunos devem ter a facilidade de se locomover no ambiente escolar, sem dificuldades que tornem sua rotina ainda mais diferente da dos demais colegas (MAZZARINO; FALKENBACH; RISSI, 2011).

A inclusão deve pensar de forma macro, em todo o processo inclusivo. $O$ aluno deve ter uma recepção adequada na escola, deve ter seus passos e seu aprendizado pensados de forma a condizer com suas necessidades. Para que isso ocorra, é necessária uma adaptação em toda a estrutura da escola, respeitando cada deficiência como única. Alguns recursos existentes contribuem com esse processo, como os elevadores sonoros, plataformas de elevação, piso tátil e outros (MAZZARINO; FALKENBACH; RISSI, 2011). Compreendendo que existem recursos tecnológicos e o preparo da escola para o processo inclusivo, há ainda que se falar na parte talvez mais importante: a metodologia. 


\section{AKED』A}

De nada adiantará a escola possuir estrutura adaptada e recursos tecnológicos de ponta se a metodologia aplicada em sala de aula destoar desse propósito. Há que se pensar estratégias pedagógicas, de forma a promover a inclusão de todos os alunos, e não somente dos que possuem algum tipo de dificuldade (ROSA, 2015).

Até nessa etapa, a ferramenta tecnológica pode contribuir. Um exemplo disso é um projeto da MICROSOFT que busca disseminar a linguagem de programação entre crianças com deficiência visual, através de uma programação que utiliza o método tátil, com blocos modulares coloridos, de diferentes formas e tamanhos, que correspondem a comandos específicos (ROSA, 2015).

A metodologia STEM também contribui, trazendo técnicas que englobam a Ciência, Tecnologia, Engenharia e Matemática, trazendo para o ambiente escolar uma experiência de ensino que promove a lógica, a criatividade, mais dinamismo nas tarefas, uma melhor compreensão do conteúdo e bastante trabalho em equipe (ROSA, 2015).

\section{CONCLUSÃO}

O desenvolvimento da presente pesquisa sobre como compreender a importância das tecnologias acessíveis para deficientes visuais no ambiente escolar, mostrou a relevância que os softwares têm sobre a vida de um aluno deficiente visual. O uso de programas como o DosVox, Jaws, Virtual Vision e outros citados no texto, permite que o aluno possa ser incluído em uma sala de aula de ensino regular, e que sua identidade e autonomia se intensive, tornando sua aprendizagem mais significativa.

$\mathrm{Na}$ pesquisa pode-se notar 0 grande número de aplicativos, equipamentos e softwares que são possíveis para que essa inclusão aconteça, além de uma gestão e equipe escolar preparada para essas tecnologias e para o aluno deficiente visual.

A partir disso, conclui-se que há diversas ferramentas tecnológicas para aluno cego ou com baixa visão e essas ferramentas possibilitam um processo mais assertivo de inclusão e de ensino aprendizagem. 


\section{REFERÊNCIAS}

ABNT. Associação Brasileira de Normas Técnicas. ABNT NBR 15599: 2008. Disponível em: https://www.abntcatalogo.com.br/horma.aspx?ID=145. Acesso em: 09 de setembro de 2020 .

BRASIL. Decreto n. 5.296 de 02 de dezembro de 2004. Regulamenta as Leis $\mathrm{n}$ 10.048 , de 8 de novembro de 2000 , que dá prioridade de atendimento às pessoas que especifica, e 10.098, de 19 de dezembro de 2000, que estabelece normas gerais e critérios básicos para a promoção da acessibilidade das pessoas portadoras de deficiência ou com mobilidade reduzida. Brasília DF, dez 2004.2 Disponível em: http://portal.mec.gov.br/seesp/arquivos/pdf/decreto\%205296-2004.pdf. Acesso em: 02 de setembro de 2020.

CARVALHO, J. O. F. Interfaces para o Deficiente Visual. Revista Informédica. Campinas: Instituto de Informática da Pontifícia Universidade Católica, 1993. Disponível em: http://www.informaticamedica.org.br/informed/defic.htm. Acesso em: 02 de setembro de 2020.

CARVALHO, R. Cartografia do Trabalho Docente na e para a Educação Inclusiva. São Paulo, 2008.2 Disponível em: http://arquivos.cruzeirodosuleducacional.edu.br/principal/old/revista educacao/ pdf/volume 2/rev n\%C2\%BA2 2 carvalho.pdf. Acesso em: 08 de setembro de 2020.

CARVALHO, F. C. A. A Inclusão do Aluno com Deficiência no Ensino Regular e o uso das Ferramentas Pedagógicas na Aprendizagem. Monografia UAB/UnB. Brasília, 2011. Disponível em: https://bdm.unb.br/bitstream/10483/2312/1/2011 FranciscaCleaAlmeidadeCarv alho.pdf. Acesso em 22 de setembro de 2020.

CORSI, M. G. F. Adaptação de material pedagógico para crianças com visão subnormal: necessário por que? In: Visão subnormal: intervenção planejada. São Paulo: Vida e Consciência, 2001, p. 71-89.

FREIRE, F. M. P.; VALENTE, J. A. Aprendendo Para a Vida: os computadores na sala de aula, São Paulo: Cortez Editora, 2003.

JECRIPE. Jogos de estímulo criados para pessoas especiais. S/d. Disponível em: https://jecripe.wordpress.com/. Acesso em: 09 de setembro de 2020.

KASTRUP, V. Experiência Estética Para Uma Aprendizagem Inventiva: notas sobre a acessibilidade de pessoas cegas a museus. Informática na Educação: teoria e prática, Porto Alegre, v. 13, n. 2, p. 38-45, 2010. Disponível em: https://seer.ufrgs.br/InfEducTeoriaPratica/article/view/12463/13435. Acesso em: 02 de setembro de 2020. 
MAGRI, C. Avaliação da Acessibilidade e da Usabilidade de um Modelo de Ambiente Virtual de Aprendizagem Para a Inclusão de Deficientes Visuais. Universidade de São Carlos, $2011 . \quad$ Disponível em:https://repositorio.ufscar.br/bitstream/handle/ufscar/3670/3683.pdf?sequenc e=1\&isAllowed=y. Acesso em: 07 de setembro de 2020.

MAZZARINO, J. M.; FALKENBACH, A.; RISSI, S. Acessibilidade e inclusão de uma aluna com deficiência visual na escola e na educação física. Rev. Bras. Ciênc. Esporte (Impr.), Porto Alegre, v. 33, n. 1, p. 87-102, mar.2011. Disponivel em: https://www.scielo.br/scielo.php?pid=S0101$32892011000100006 \&$ script=sci abstract\&tlng=pt. Acesso em: 23 de setembro de 2020.

MEC. Ministério da Educação. Grafia Braille para a Língua Portuguesa. 3.ed. Ministério da Educação. 2018.2 Disponível em: http://portal.mec.gov.br/docman/dezembro-2018-pdf/104041-anexo-grafiabraille-para-lingua-portguesa/file. Acesso em: 12 de setembro de 2020.

NACARATO, A. M.; MENGALI, B. L. S.; PASSOS, C. L. B. (Coord.). A matemática nos anos iniciais do ensino fundamental: Tecendo fios do ensinar e do aprender. Belo Horizonte: Autêntica, 2009. (Coleção Tendências em Educação Matemática).

OLIVEIRA, C. de; MOURA S. P.; SOUSA, E. R. de. TIC'S na educação: a utilização das tecnologias da informação e comunicação na aprendizagem do aluno. Monografia UESPI-Campus Dom José Vásquez Díaz, 2015.

PARAGUAY, A. I. B. B. et al. Tecnologia Assistiva. Brasília: SEDH, 2009. Disponível em: http://www.galvaofilho.net/livro-tecnologia-assistiva CAT.pdf. Acesso em: 02 de setembro de 2020.

RABELLO, S. Introdução. O Uso do Computador no Desempenho de Atividades de Leitura e Escrita do Escolar com Deficiência Visual. Campinas, $2007 . \quad$ Disponível em: http://intervox.nce.ufri.br/dosvox/textos/tese suzana rabello.pdf. Acesso em 22 de setembro de 2020.

RIBEIRO, L. A Inclusão do Aluno com Deficiência Visual em Contexto Escolar: Afeto e Práticas Pedagógicas. Revista Educação, Artes e Inclusão, v.13, № 1, $2017 . \quad$ Disponível em: https://www.revistas.udesc.br/index.php/arteinclusao/article/view/9287. Acesso em: 07 de setembro de 2020 .

ROSA, E. A. C. O que é uma escola inclusiva? Um estudo sobre práticas e metodologias em Educação Matemática. 2015. Disponível em: https://www.ufjf.br/ebrapem2015/files/2015/10/gd13 erica rosa.pdf. Acesso em: 22 de setembro de 2020.

SONZA, A. P. Acessibilidade de Deficientes Visuais aos Ambientes Digitais. (Dissertação) Pós-graduação em Educação da Faculdade de Educação da Universidade Federal do Rio Grande do Sul. Porto Alegre, 2004. Disponível 


\section{AKED』A}

em: https://lume.ufrgs.br/handle/10183/5626. Acesso em: 22 de setembro de 2020.

SONZA, Andréa Poletto; CONFORTO, Débora; SANTAROSA, Lucila. Acessibilidade nos portais da educação profissional e tecnológica do ministério da educação. Revista Brasileira da Educação Profissional e Tecnológica, [S.I.], v. 1, n. 1, p. 131-145, jul. 2015. ISSN 2447-1801. Disponível em: http://www2.ifrn.edu.br/ojs/index.php/RBEPT/article/view/2874. Acesso em: 24 de setembro de 2020.

TOMAZ, L. Da robótica à impressão 3D: projeto inovador de colégio estadual estimula habilidades e empreendedorismo. Ago. 2019. Disponível em: http://www.consed.org.br/central-de-conteudos/da-robotica-a-impressao-3dprojeto-inovador-de-colegio-estadual-estimula-habilidades-eempreendedorismo. Acesso em: 15 de setembro de 2020.

TORNIERO, G. Aplicativos para pessoas com deficiência: como a inteligência artificial pode melhorar a vida de milhões de brasileiros. BBC News Brasil - 20 janeiro 2019. Disponível em: https://www.bbc.com/portuguese/geral-46685874. Acesso em: 10 de setembro de 2020. 